\title{
Endoscopic ultrasound-guided biliary drainage in a novel radiofrequency ablation-based swine biliary dilatation model
}
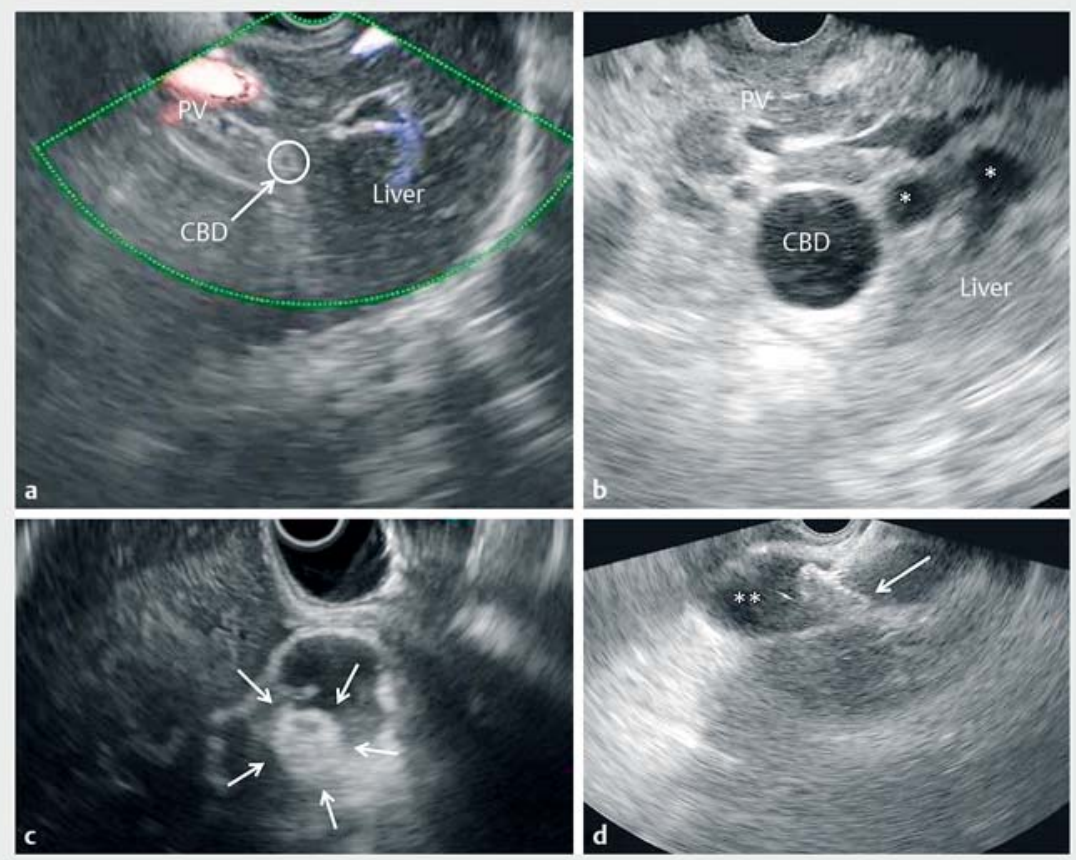

- Fig. 1 Endoscopic ultrasound images in a minipig model showing: a the normal common bile duct (CBD) and portal vein (PV) at the hepatic hilum viewed from the stomach before radiofrequency ablation (RFA) of the distal CBD; $\mathbf{b}$ the distal CBD viewed from the stomach following RFA with evidence of dilatation of the CBD and intrahepatic biliary ducts $\left({ }^{*}\right)$; $\mathbf{c}$ the RFA-induced hyperechoic lesion (arrows) in the distal CBD seen from the bulb; $\mathbf{d}$ the distal flange of the lumen-apposing metal stent, seen from the gastric antrum and correctly deployed in the distended gallbladder $\left({ }^{* *}\right)$.

Endoscopic ultrasound (EUS)-guided drainage procedures are becoming increasingly widespread in clinical practice, even though they are technically challenging and require a substantial learning curve. In vivo swine biliary dilatation models for training have been described; however, they provide erratic biliary dilatation and can also be technically cumbersome [1-5]. We describe EUS-guided gallbladder drainage with a lumen-apposing metal stent (LAMS) in a novel swine biliary dilatation model.

A 30-kg minipig underwent endoscopic retrograde cholangiography and temperature-controlled endobiliary radiofrequency ablation (EB-RFA) of the distal common bile duct (CBD) with a dedicated RFA system (ELRA, STARmed) ( $\vee$ Video 1 ). The ablation consisted of $10 \mathrm{~W}$ of power delivered via an endobiliary catheter-electrode, with a temperature sensor at a target temperature of $80^{\circ} \mathrm{C}$, for two rounds of 90 seconds. After 11 days, the pig was re-examined with a linear EUS scope, which revealed dilatation of both the intrahepatic and extrahepatic biliary ducts, including the gallbladder. At the distal third of the CBD, an RFA-induced hyperechoic lesion was detected (> Fig.1).

The distended gallbladder was accessed from the gastric antrum with a $19 \mathrm{G}$ needle (Expect, Boston Scientific). A 0.025-

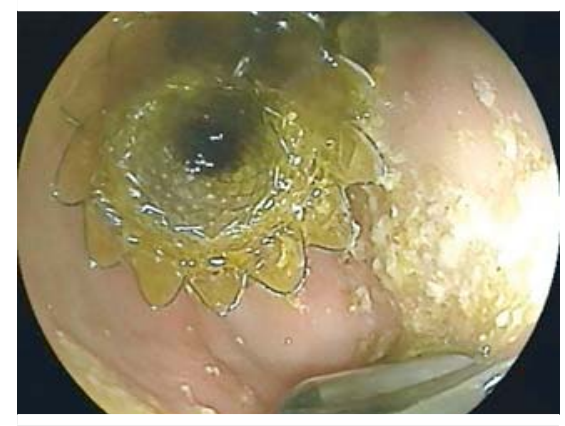

- Fig. 2 Endoscopic view showing the proximal flange of the lumen-apposing metal stent correctly deployed in the gastric antrum.

inch guidewire (VisiGlide 2, Olympus) was then inserted through the needle and coiled into the gallbladder. After a cholecystogastric fistula had been created using a wire-guided needle knife (MicroKnife, Boston Scientific), the tract was dilated with a 6-mm balloon (Hurricane, Boston Scientific). Finally, a $10 \times$ 20-mm LAMS (Spaxus, Taewoong) was placed under combined EUS, fluoroscopic, and endoscopic guidance ( $\triangleright$ Fig. 2).

Temperature-controlled EB-RFA of the distal CBD proved to be a straightforward, effective, and novel technique to create a biliary stricture with subsequent massive upstream biliary dilatation. EUSguided gallbladder drainage with a LAMS was feasible in this model, which is theoretically suitable also for other EUS-guided biliary interventions. Furthermore, the swine model provides excellent haptic feedback and suitable levels of realism in comparison to procedures undertaken in humans.

Endoscopy_UCTN_Code_TTT_1AU_2AB

Competing interests

None 


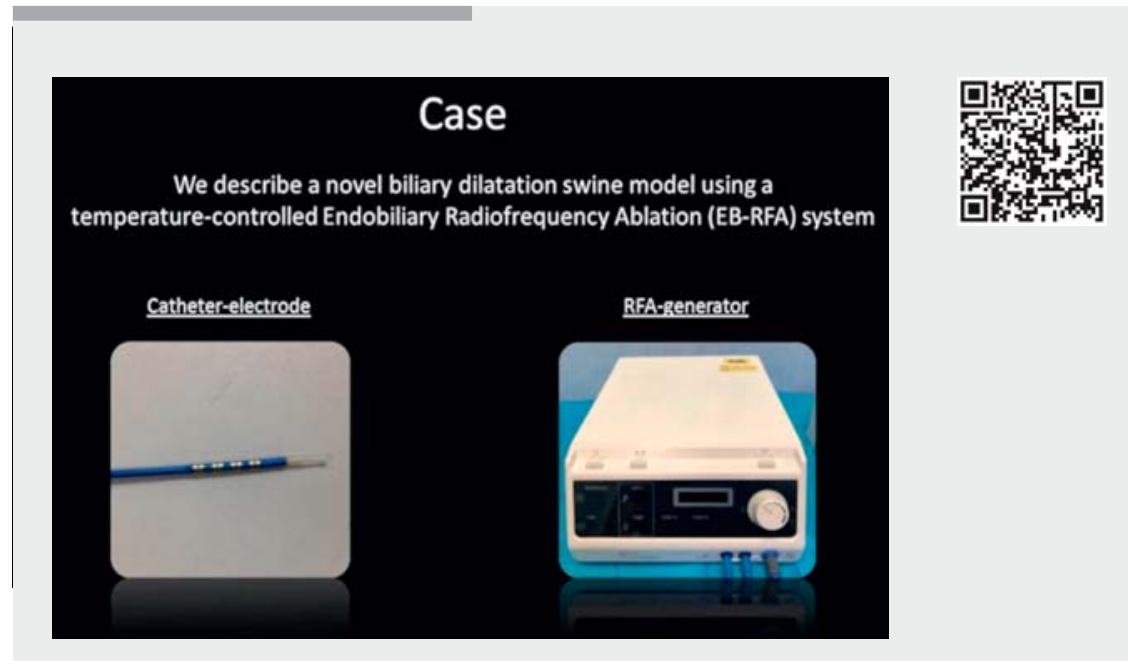

Video 1 Video showing endoscopic ultrasound-guided biliary drainage with a lumenapposing metal stent in a novel swine biliary dilatation model obtained with a temperature-controlled endobiliary radiofrequency ablation system.

The authors

Dario Ligresti ${ }^{1}$, Stefano Baraldo ${ }^{2}$, Radhika

Chavan $^{3}$, Margaret Geri Keane ${ }^{4}$, Yu-Ting Kuo ${ }^{5}$, Shaimaa Saleem ${ }^{6}$, Dong-Wan Seo $^{7}$

1 Endoscopy Service, Department of Diagnostic and Therapeutic Services, IRCCSISMETT, Palermo, Italy.

2 Department of Endoscopy, Barretos Cancer Hospital, Barretos, Brazil

3 Department of Medical Gastroenterology, Asian Institute of Gastroenterology, Hyderabad, India

4 Institute of Hepatology, Kings College Hospital, London, UK

5 Division of Endoscopy, Department of Integrated Diagnostics and Therapeutics, National Taiwan University Hospital, Taipei, Taiwan

6 Gastroenterology and Endoscopy Department, Ahmed Maher Teaching Hospital, Cairo, Egypt

7 Department of Gastroenterology, Asan Medical Center, University of Ulsan College of Medicine, Seoul, South Korea

[3] Minaga K, Kitano M, Itonaga M et al. Endoscopic ultrasound-guided biliary drainage using a newly designed metal stent with a thin delivery system: a preclinical study in phantom and porcine models. J Med Ultrason 2018; 45: $391-397$

[4] Park JS, Jeong S, Kim JM et al. Development of a swine benign biliary stricture model using endoscopic biliary radiofrequency ablation. J Korean Med Sci 2016; 31: 1438 1444

[5] Rumalla A, Petersen BT, Baron TH et al. Development of a swine model for benign stenosis of the bile duct by endoscopic application of intraluminal thermal injury. Gastrointest Endosc 2003; 57: 73-77

\section{Bibliography}

DOI https://doi.org/10.1055/a-0867-9348

Published online: 1.4.2019

Endoscopy 2019; 51: E162-E163

(c) Georg Thieme Verlag KG

Stuttgart · New York

ISSN 0013-726X

Corresponding author

\section{Dong-Wan Seo, MD, PhD}

Department of Gastroenterology, Asan Medical Center, University of Ulsan College of Medicine, 88 Olympic-ro 43-gil, Songpa-gu, Seoul 05505, South Korea Fax: +82-2-4760824

dwseoamc@amc.seoul.kr

\section{References}

[1] Lee TH, Choi JH, Lee SS et al. A pilot proof-ofconcept study of a modified device for onestep endoscopic ultrasound-guided biliary drainage in a new experimental biliary dilatation animal model. World J Gastroenterol 2014; 20: 5859-5866

[2] Alcaide N, Lorenzo-Pelayo N, Ruiz-Zorrilla R et al. Endoscopic porcine model of biliary obstruction using over-the-scope clips: feasibility and applicability to training in EUSguided drainage procedures. Gastrointest Endosc 2013; 77: AB294-AB295

\section{ENDOSCOPY E-VIDEOS}

https://eref.thieme.de/e-videos

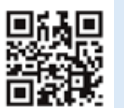
Endoscopy E-Videos is a free access online section, reporting on interesting cases and new

techniques in gastroenterological endoscopy. All papers include a high quality video and all contributions are freely accessible online.

This section has its own submission website at https://mc.manuscriptcentral.com/e-videos 